\title{
O ENSINO DE PSICOLOGIA NO SÉCULO XIX NA CIDADE DO RIO DE JANEIRO
}

Marina Massimi*

\section{Resumo}

Objeto do artigo sāo os conhecimentos psicologicos transmitidos e produzidos em instituiçōes de ensino superior e secundário na cidade do Rio de Janeiro, durante o século XIX (até 1870), visando-se evidenciar por meio da análise crítica a significação conceitual e a funçăo social dos mesmos no âmbito do contexto brasileiro da época.

Através de um levantamento de material documentário relativo a algumas escolas importantes do Rio de Janeiro, no século XIX, foi possível reconstruir o quadro dos conteudos e das práticas psicológicas objeto de ensino e de elaboração em tais escolas, evidenciando-se a coexistência de diferentes propostas em termos de abordagens doutrinárias, de enfoques metodologicos, de objetivos visados.

\section{INTRODUÇAO}

O ensino e a elaboraçāo de conhecimentos psicológicos no âmbito de importantes instituiçōes escolares de nf́vel superior e secundário da cidade do Rio de Janeiro, no século XIX, é um fato documentado pela análise do material histórico relativo a atuação cultural de tais instituiçōes na época'.

O exame de currículos escolares, compêndios, relatórios, teses e dissertaçōes, livros e artigos elaborados por professores ou alunos membros das escolas consideradas atesta a presença difusa de um interesse por assuntos denominados ora como "Psychologia", ora como "Therapeutica Moral". Para entender a significação desse interesse é preciso compreendê-lo no âmbito do contexto cultural da cidade do Rio de Janeiro no século XIX.

Com efeito, no Rio de Janeiro, Capital do Império, concentravam-se todas as instâncias renovadoras e propulsoras no campo intelectual e político, como documentam algumas iniciativas: tem-se, por exemplo, a criaçāo da Imprensa Régia (1808), da Biblioteca Pública (1810), do Museu Nacional (1814), da Escola de Belas Artes (1814), das Academias da Marinha e Militar (1810). O Curso de Cirurgia e Anatomia, criado em 1808, foi transformado, logo depois (1809), em Curso de Medicina e, sucessivamente, em Faculdade de Medicina (1832). Surgiram também vários cursos profissionalizantes. "Aulas Régias" eram

- Docente do Departamento de Psicologia e Educaçáo da Paculdade de Filosofia, Ciencias e Letras de Ribeirlo Preto - USP

1. Em particular, considera-sé duas escolas de formaçăo religiosa (o Seminário Săo José e o Mosteiro Sáo Bento) e duas escolas públicas (o Colégio Pedro II e a Faculdade de Medicina). 
ministradas nos Seminários de São Joaquim e de São José e no Mosteiro Beneditino que, no período, era muito ativo culturalmente. A partir de 1732, funcionava também o Seminário de São José, destinado à formação do clero, oferecendo cursos de Filosofia e Teologia.

Um evento de grande importância no panorama cultural do Rio foi a conversāo do antigo Seminário de São Joaquim (fundado no século XVIII) em Colégio D. Pedro II em 1837: tal instituiçäo deveria ser o modelo do ensino secundário para toda a Nação; o plano de estudos do Colégio tinha matrizes no enciclopedismo, nas idéias da Revolução Francesa e no ecletismo.

Normal do Brasil.

Além disso, em Niterói, foi criada, em 1835, a primeira Escola

A influência francesa dominava o clima cultural da cidade do Rio: a "Missāo Artística" de 1816 foi um evento importante em que vários artistas e intelectuais de França foram convidados a organizar uma Escola Régia de Ciências, - Artes e Of́́cios, destinada a formaçấo nāo apenas de funcionários governamentais, mas também de profissionais nas áreas de agricultura, industria e comércio.

Existiam ainda, no Rio de Janeiro, várias Academias e Sociedades Culturais, entre as quais a "Academia Filosofica", fundada em $1857 \mathrm{com}$ o objetivo de estudar o esjírito humano e constiturda principalmente por médicos. Tais entidades publicavam, em muitos casos, jornais e revistas. Entre outras publicações, citamos a Minerva Brasiliense (fundada em 1845), posteriormente chamada Guanabara (1851); a Aurora Fluminense (1827); e o Médico do Povo na Terra de Santa Cruz (1864).

A cidade constituía, em suma, um terreno fecundo e receptivo de fermentos doutrinários e propostas culturais novas, ao mesmo tempo em que mantinha vivas as raizes da tradição intelectual mais antiga.

Este contexto parece propício para o desenvolvimento de uma disciplina com uma longa história mas com uma função social e proposta metodológica novas, como será a Psicologia do século XIX.

\section{"Psychologia" nas Escolas do Blo de Janeiro}

\section{A "Psychologia" no Mosteiro de Såo Bento}

No Mosteiro Beneditino do Rio de Janeiro funcionava desde 1857, além dos estudos do noviciado, um Externato que possura um curso primário, um secundário e um superior. Chamava-se "Colégio São Bento" e contava, em 1857, 300 alunos matriculados; em 1858, 600 alunos, numero que dobraria no ano seguinte. Entre outras matérias, o curso secundário oferecia a Filosofia Racional

Paidéia, FFCLRP - USP, Rib. Preto, 4, Fev/Jul, 1993. 
e Moral. Vários monges foram também professores de Filosofia e de diferentes disciplinas, inclusive em outras instituiçöes. Entre os mais ilustres, encontram-se frei Policarpo de Santa Geltrudes, docente no Seminário de São Joaquim, por volta de 1830; frei Rodrigo de S. José Pereira Vice-Reitor e professor do Colégio Pedro II desde 1839 até 1851; frei José de Santa Maria Amaral, docente de Filosofia (desde 1851 até 1866) e posteriormente Reitor do mesmo Colégio.

O noviciado, cujo currículo era baseado no Plano e Regulamento dos Estudos para a Congregacăo de Sāo Bento de Portugal (1789), era organizado em quatro níveis: o noviciado propriamente dito, o curso de Humanidades, 0 curso de Filosofia, e o de Teologia. $O$ curso de Filosofia durava três anos e inclura, entre as materias do terceiro ano, a "Pneumatologia", ou seja, o estudo dos espiritos. A pneumatologia abrangia o conhecimento da alma humana bem como das demais entidades imateriais.

Pode-se supor que conhecimentos psicologicos foram elaborados e transmitidos pelos Beneditinos no Mosteiro e nas outras instituiçōes em que exerciam influencia cultural. Nesse sentido, citamos aqui dois exemplos. 0 primeiro e o do já nomeado frei Policarpo de Santa Geltrudes, sob cuja orientação foram redigidas por J. de Sequeira Queiroz, Jose J. Pereira e Antonio Máximo de Couto, as Theses Philosophicas sobre Psychologia do Homem, defendidas em público no Imperial Seminário de São Joaquím, em 1830 . Inspiradas no sensualismo, as teses abordam varios temas: a natureza da alma humana; as suas sensaçōes e as idéias, a consciência; o prazer e a dor; desejos, voliçōes e liberdade; a moralidade do homem. A sensaçāo é definida como "modificação da alma sempre precedida do movimento nos orgảos, excitados pela acção dos corpos" (1830, p. 2). Particularmente interessante e a definiçăo da função do "Psychologista, cujo interessante $\epsilon$ a definição da funçăo do "Psychologista, cujo intento he de conhecer os phenomenos da intelligencia" (p. 1), por contraposição ao "psyologista", que estuda o corpo humano.

Por sua vez, o monge Beneditino frei Saturnino de Santa Clara Antunes de Abreu, professor no Imperial Colégio Pedro II, é conhecido por uma "arguição" sobre as origens das idéias, pronunciada por ocasiāo do Concurso para a Cadeira de Filosofia no mesmo instituto. $O$ relato do Concurso encontra-se em alguns artigos de 1844, publicados na revista Minerva Brasiliense (1844, a, b , c). Santiago Nunes Ribeiro, autor dos artigos, define frei Saturnino, juntamente com outro monge defensor de Condillac, frei P.M. Paulo, como um adepto do sensualismo.

Contudo, a presença da tradição aristotélico-tomista na formação dos beneditinos é documentada pelos manuais inspirados nessa escola, disponiveis na Biblioteca do Mosteiro. Entre outros, destaca-se o Elementa Philosophiae Christianae (1862) de Sanseverin. Nessa abordagem, a Psicologia é estruturada em "Dynamologia" - que é propriamente o estudo das faculdades da alma - e "Antropologia", ou seja, o conhecimento do ser humano considerado como unidade composta de corpo e alma. 


\section{A "Psychologia" no Seminario de São José}

O Seminário de São José foi fundado em 1739 pelo bispo Dom Antonio de Guadalupe. Em seu relatório de viagem ao Brasil em 1823, Spix e Martius assinalaram o Lyceu do Seminário São José como "o melhor colégio... onde, a par do latim, do grego, do francez, do inglez, da rhetorica, da geografia e da mathematica também se ensinam philosophia e theologia" (Doria, 1937, p. 11).

Inicialmente inspirado nos ideais da reforma tridentina, o programa de formação do clero no Seminário diocesano sofreu várias transformaçôes ao longo do século XVIII e do século XIX. Sobretudo na época do pontificado do bispo José Caetano da Silva Coutinho (de 1803 ate 1833) a cultura da instituição foi permeada pelas doutrinas regalistas e jansenistas elaboradas na Universidade de Coimbra. Os manuais encontrados na Biblioteca da instituigsa fornecem indícios sobre os contéados psicológicos no currículo de estudo. Na áred filosófica, comparecem vários textos de inspiraçāo tomista, como os já citados Sanseverini (1862) e Soriano de Souza (1867 e 1871), contendo secçōes dedicadas a Psicologia. No campo do estudo do "espirito", destaca-se Pneumatologie (1854) de J.F. Mirville.

Entre os livros pedagogicos, o tratado De l'Education ou Principes de Pédagogie Chrétienne (1854) de L.F.F. Gauthey analisa a educação nos seus vários aspectos (físico, rensorial, intelectual e moral) e define as relaçỏes de complementaridade entre Pedagogia e Psicologia, afirmando que, para cultivar as faculdades do homem, é preciso antes conhecé-las.

De particular interesse são os manuais de Teologia Moral, como a Theologia Moralis(1850) de P. Scavini; o Manual dos Confessores (1862) de P. Gaume; as Oeuvres Completes (1842) de A.M. de Liguori. A análise desse material reveta, na Teologia Mioral do periodo, uma elaboração muito detalhada das 'técnicas' de confissăo e um estudo bastante aprofundado das causas e da fenomenologia das inclinaçōes aos varios tipos de pecados presentes nos individuos. Tais documentos representam tentativas embrionárias de indagação psicologica acerca da personalidade e de seus desvios morais e psicológicos, sugerindo a hipótese de que, pelo menos no século considerado, a confissão assumisse quase a função de uma psicoterapia. Nesse contexto, são criticamente descritas bem como refutadas as doutrinas éticas dos filósofos materialistas da época.

\section{A "psychologia" no Imperial Colégio Pedro II (ex-Seminário São Joaquim)}

No Seminário São Joaquim, fundado no século XVIII, destinado à formação dos jovens cariocas, dava-se ênfase particular no estudo da Filosofia. As Preleccōes Filosoficas de Silvestre Pinheiro Ferreira foram escritas como texto-base de um curso por ele ministrado para os alunos do Seminário desde 1813 até 1816. Publicadas naquela época em forma de fascículos autônomos, as 
Preleccões constituem um simples roteiro esquemático do curso e compreendem vários tópicos de Psicologia (sobretudo na ultima parte do livro), seguindo uma abordagem de inspiração aristotélico-tomista. O Compêndio de Filosofia, reunindo o conterado dessas preleçōes, foi publicado sucessivamente pelo autor em Paris, em 1839, com o título de Nocōes Elementares de Philosophia, Geral e Aplicada às Sciencias Moraes e Políticas, Ontologia, Psychologia e Ideologia. Outro documento sobre esse interesse por tópicos psicologicos, nos estudos filosoficos do Seminário, são as Theses Philosophicas sobre a Psychologia do Homem (1830) do beneditino frei Policarpo de Santa Geltrudes, mencionadas acima.

Após várias reformas (em 1821, em 1831 e em 1837), o Seminário foi transformado, por decreto de 31 de janeiro de 1838, no Imperial Colégio Pedro II. De instituição eclesiástica, tornou patrimônio do Estado e estabelecimento modelo das escolas secundárias do Império. Comentando a importância do novo Colégio para a sociedade brasileira, escreve o Jornal do Comércio (D6ria, 1937, pp. 18-19) que tal estabelecimento "tende a preparar a nova geração que há de se reger os futuros destinos do paiz de uma maneira mais ampla já nos princcípios adquiridos em prática... já pelos certames scientificos que ahi colherá em sucessão de estudos clássicos e progressisticos. Faltava ao Brasil hum semelhante estabelecimento, uma escola progressiva de educação à mocidade, como disse o ministro do Imperio, que servisse de typo as outras que se acham em actividade no paiz..."

O plano de estudos da escola, elaborado com base nos critérios e objetivos progressistas explicitados pelos seus fundadores, inclui também a disciplina psicologica. $O$ interesse pela Psicologia, com efeito, é documentado, em vários níveis, quer nos programas dos cursos, quer nos manuais usados, quer na produção cultural dos professores do Colégio. Uma primeira expressāo do interesse pelos assuntos psicológicos difundido no ambiente cultural do Colégio é constituído pelo já citado relato do "Concurso à Cadeira de Philosophia no Colégio Dom Pedro II", realizado no dia 9 de julho de 1844. O relato, elaborado por Santiago Nunes Ribeiro, foi publicado em 1844 na revista Minerva Brasiliense (1844, a , b, c). O tema da dissertação proposta aos candidatos era: "as idéías inatas e as várias teorias a respeito". A Comissão Examinadora era composta pelo Ministro do Império, o Conselheiro Paiva Guedes; pelo Reitor do Colégio, Joaquim Caetano da Silva e por dois beneditinos, frei P.M. Paulo e frei Custódio Alves Serrão. Os concorrentes eram quatro: Sales Torres Homem, F. de Sales Brasil; e dois alunos da Escola de Medicina da Corte, Maximiano e Heredia. A exposição dos candidatos e a arguição dos examinadores refletem a presença de diferentes tendências filosóficas na cultura carioca e, em particular, no âmbito do Colégio: o empirismo e o sensualismo dos dois professores beneditinos, o espiritualismo eclético de Joaquim Caetano da Silva e de S. Torres Homem e o reducionismo mecanicista do médico Heredia. A respeito desse Gltimo, Nunes Ribeiro comenta: "O Sr. Heredia explica os fatos psychologicos por meio de correntes electricas e outras forças materiaes. Diz elle que os sentidos recebem a impressão do objecto externo e que por meio das correntes 
electricas dão parte ao cérebro do que se passa nelles; o cérebro, que faz o officio de introductor, dá parte disto à alma, que está no interior da casa... O Sr. Heredia ha de saber que Boerrhave, e Hoffman, e outros, formam a escola de medicina chamada "mechanica" e "hydraulica". Ora, se o Sr. Heredia completar a sua theoria psychologica, não teremos huma escola mechanica em Psychologia?" (1844, p. 549).

Os programas de cursos e de exames da escola, a partir de 1850, indicam que o ensino da Filosofia, ministrado por diferentes professores (frei José de S.M. Amaral; frei Saturnino de S. Clara Antunes de Abreu; e Joaquim P. Brasil), inclúa, no sexto e sétimo anos de curso, a "psychologia como matéria propedêutica, sendo a orientação inspirada no espiritualismo eclético. (Uma descrição dos programas de curso e de exames de Psicologia da escola encontra-se nas Tabelas 1, 2 e 3).

A partir de 1857, com base no Decreto no 2006 de 24/10/1857, o ensino da Filosofia no sexto ano é dividido em Logica e Metafísica, tendo como texto-base, o Curso Elementaire de Philosochie de E. Barbe. $O$ estudo das faculdades da alma (sensibilidade, entendimento e vontade) e das diferentes operaçōes do entendimento, faz parte da Logica; enquanto que o conhecimento do eu, das operaçōes da sensibilidade e vontade, das relaçōes entre corpo e alma e da natureza da mesma, são objetos da Metafísica. A partir de 1870, pelo Decreto ne 4468 do Ministro Paulino José Soarez de Souza, o ensino da Filosofia, no sexto ano do cu.so, e bipartido em "Psychologia" e "Logica", sob a responsabilidade do professor frei Saturnino de Santa Clara Antunes de Abreu. No sétimo ano, a Filosofia compreende Metafísica, Ética e Sistemas comparados de Filosofia. O manual utilizado para o ensino da Psicologia é a tradução de Barbe, feita por Alves de Souza, juntamente com as apostilas do professor. Em 1877, este texto foi substituído pelo compêndio Precis d'un Cours Complet de Philosophie Elementaire de Pellissier, traduzido por E. Zaluard. Em 1876, pelo Decreto $n^{\circ} 6130$ do Mínistro Jose Bento da Cunha e Figueiredo, o ensino da Filosofia foi transferido para o quarto ano de curso, mantendo-se os contérdos dos planos de estudos anteriores.

Os manuais de Filosofia indicados nos Programas ou encontrados na antiga Biblioteca do Colégio são, na maioria, escritos por autores franceses e, às vezes, traduzidos em português num sinal claro da influência exercida pela cultura francesa no ensino da escola. Além do já citado Barbe, manual oficialmente adotado pela escola desde 1858, destacam-se as Questōes de Philosophia de A. Charma, da Universidade de Paris. Há muitíssimos compêndios de cunho espiritualista, como o famoso Cours de Philosophie (1837) de M. Ph. Damiron, que, segundo S. Nunes Ribeiro (1844, p. 646), foi o "texto para as lições de Philosofia que se dão no Imperial Collegio de Pedro II", escolhido pelo Reitor J. Caetano da Silva e pelo então professor Gonçalves de Magalhães. O texto é repetidamente citado em artigos e livros de autores brasileiros da época. Outros textos são inspirados em tradiçōes filosóficas mais

Paidéia, FFCLRP - USP, Rib. Preto, 4, Fev/Jul, 1993. 
antigas, por exemplo, o empirismo moderado (as Instituiçōes de Metafísica de A. Genovesi, 1855) e o tomismo (Tongiorgi, 1862; Sulpizi, 1864; Rosmini, 1836).

Particular destaque merecem as obras filosoficas de Jose Domingos Gonçalves de Magalhães, professor no Colégio. Já pelo título pode-se reconhecer a importância que estes livros têm para a História da Psicologia no Brasil. as obras Factos do Espírito Humano (1865) impressa pela primeira vez em Roma, em 1858, e, posteriormente, em Paris (1859) e no Rio de Janeiro (1865), constitui um tratado de Filosofia espiritualista, em que a Psicologia $€$ considerada a base e o ponto de partida das disciplinas filosoficas porque "lihe dá o elemento subjectivo, e reconhece as condiçōes necessárias e absolutas da razão, objectos da metaphysica" (1865, p. 29). A Alma e o Cérebro: estudos de Psychologia e Physiologia, editado no Rio de Janeíro em 1876 e em Roma em 1878 - é uma análise crítica da Frenologia, doutrina muito difundida na Epoca cuja abordagem reduz as funçōes psicológicas a processos neurologicos.

Em suma, os conhecimentos psicologicos elaborados e transmitidos no âmbito do Colégio Imperial D. Pedro II, refletem o espírito da cultura européia da época, retratando o papel inovador exercido por tal instituição no meio educacional brasileiro.

\section{A "Psychologia" na Faculdade de Medicina.}

A Faculdade de Medicina do Rio de Janeiro foi instituída, juntamente com a da Bahia, em outubro de 1832, conforme projeto elaborado em 1830-31 pela Sociedade de Medicina e Cirurgia nos moldes dos Estatutos da Faculdade de Paris. Todavia, um embriāo da Faculdade já funcionava desde 1808, no Rio, como Cadeira de Anatomia, antes (1808-1813) e como Curso Oficial de Cirurgia, depois (1813-1832).

O Projeto da Faculdade, elaborado pela Sociedade de Medicina e Cirurgia, pretende inaugurar um novo estilo de Medicina Social inspirado no modelo frances: "As novas concepçōes de medicina - afirma Machado (1978, p. 185) - tanto no que diz respeito à sua organização interna quanto à sua inserçẩo na sociedade, articulam-se às condiçōes históricas da sociedade brasileira. Em meio à situação conturbada da época, a Sociedade de Medicina justifica sua investida através do projeto de organização de uma sociedade perfeita".

Os Estatutos da Faculdade de Medicina compreendem três cursos: Medicina (6 anos), Farmácia (3 anos) e Obstetricia (2 anos). A Faculdade tem também o objetivo de controlar o exercício da profissão: sem título aprovado ou conferido por ela ninguém poderá exercer a profissāo. No século XIX, como aponta Machado, a cultura médica torna-se o "apoio científico indispensável ao exercício do poder do Estado" (1978, p. 155). O médico assume a funçāo política de lutar "contra tudo o que na sociedade pode interferir no bem-estar físico e moral" (1978, p. 155). A Medicina transforma-se, assim, em Higiene Social, tendo por objeto a saúde pública e assumindo uma função relevante no processo de estruturação da Nação brasileira moderna. $O$ interesse pela Psicologia, presente 
nos currículos, manuais e na produçāo cultural da Faculdade, coloca-se nesse quadro, na medida em que esta disciplina oferece meios para o controle social dos indivíduos e das populaçōes e para a definição do comportamento anormal.

Nos tratados de Mariano José do Amaral (1827), e de José Maria Bontempo $(1814 ; 1815 ; 1825)$, docentes do antigo curso de Medicina e Cirurgia, destaca-se o interesse pelas "doenças nervosas", analisadas com referências explícitas às teorias da Psicopatologia francesa. Tais tipos de moléstias são definidas como "lesōes do sentimento e do movimento" (Bontempo, 1815, p. 8). Particular ênfase é dada ao estudo da hipocondria, da melancolia, da mania, da demência e das doenças nervosas de origem sexual, tanto no homem quanto na mulher. Destaca-se tambem o texto posterior de A. Mello Moraes, Physiologia das Paixōes e Affeccōes (1869), "precedida por uma noção philosophica geral e de um estudo aprofundado e descripçöes anatomicas do homem e da mulher, suas differenças physiologicas e moraes, baseadas nas theorias de Lavater, Morreau, Porta, Le Brun, Roussell, Virey e outros; seguida de uma classificação methodica de todos os sentimentos affectivos e moraes, conforme a força com que obrăm no espírito, na imaginação e no coraçāo" (subtítulo).

Documentos importantes relativos aos trabalhos tebricos desenvolvidos pelos estudantes da Faculdade, sobre temas de Psicologia, são as teses e dissertaçōes elaboradas para a obtençāo do grau de doutor. Como aponta Machado (1978), a escolha dos assuntos não reflete a presença de cursos especializados nessa área, mas apenas o interesse teórico dos alunos e a influência das doutrinas estrangeiras, sobretudo francesas, reproduzindo, no âmbito da Psicologia, às vezes com pouco rigor, os grandes temas do saber médico da época. O número elevado de tais documentos, levantados até o ano de 1870 (91, entre teses e dissertaçōes que abordam conteudos psicológicos) é indício da importância que, no perfodo, começa a ser atribuída a tais estudos. Os temas mais debatidos são: a psicologia da mulher, as doenças relacionadas à sexualidade e aspectos psico-sociais do casamento e da relação familiar; higiene da infância e da adolescência; higiene de algumas instituiçōes como escolas e prisōes; a alienaçăo mental e as analogias entre o homem alienado e o normal; o suicídio; emoçōes e afetos; influências do estado moral do homem sobre o estado físico, e vice-versa; o desenvolvimento do homem nas diferentes idades e problemas da velhice; a Frenologia; o conceito de "força nervosa"; a "therapeutica moral".

E muito acentuada a tendência a enfocar o homem na sua totalidade, atribuindo-se ao médico a tarefa de direcionar convenientemente o estado físico e as faculdades morais do paciente. J.P. La Cour, por exemplo, afirma que "a direcção convenientemente regulada das faculdades moraes, recebendo a impulsão por parte do médico experimentado, torna-se em certas occasiōes uma alavança efficaz e segura" (1863, p. 7). O tratamento moral é recomendado também na terapia da alienação mental. 
A "therapeutica moral", assim elaborada, assemelha-se, por certos aspectos, à moderna psicoterapia. Todavia, sua peculiaridade está na ênfase dada ao componente moral e comportamental dos disturbios psíquicos, tentando o discurso médico definir-se como concepsão abrangente da totalidade do ser humano. Dessa forma, o humanitarismo médico se substitue à antropologia e à ética da matriz religiosa que marcaram a cultura colonial.

Outras fontes uteis para a reconstrução histórica do pensamento dos médicos cariocas do século XIX, acerca da Psicologia, são constituídos pelos Relatorios da Sociedade da Academia Nacional de Medicina (Simoni, 1831) do Rio de Janeiro e pelas revistas publicadas na área, como o Arquivo Médico Brasileiro e os Annaes Brasilienses de Medicina. Alguns dos artigos publicados abordam assintos psicologicos. Em alguns casos, tais artigos săo simples traduçōes de textos impressos em Revistas estrangeiras (ex: Barbier, 1855; Devay, 1851; Albers, 1853). Em outros casos, eles constituem informes acerca dos conhecimentos nessa área desenvolvidos em outras naçōes, principalmente Inglaterra, França, Portugal, EUA (Rodrigues, 1845; Lapa, 1846; Torres Homem, 1844). Uma referência à situação brasileira encontra-se no artigo de J.P. Rego sobre a hipocondria na primeira infância (1851), em que o autor aborda o tema dos distúrbios psíquicos sofridos pelas crianças negras devido à condição de escravidāo.

Além disso, os médicos escrevem artigos em revistas não especializadas de divulgaçāo mais ampla como, por exemplo, a Minerva Brasiliense, Guanabara, a Revista Popular, Iris, o Médico do Povo na Terra de Santa Cruz.

Em conclusāo, as instituiçōes do saber médico desenvolveram na cidade do Rio de Janeiro, ao longo do século XIX, um papel social e cultural muito relevante. A Psicologia nelas elaborada e divulgada apresenta-se como meio de higiene e controle social da população, e as frequentes referências à Psicologia européia colocam-se no quadro da tentativa de assimilar o mais possível a nação brasileira aos Estados europeus modernos.

\section{CONCLUSÃO}

A análise dos documentos relativos às atividades de ensino e produção cultural realizadas em algumas importantes instituiçōes escolares do Rio de Janeiro, no século XIX, evidencia a presença de uma variedade de conhecimentos psicológicos, espalhados em diferentes áreas do saber, desde a Metafísica e a Teologia Moral até à Medicina Social e à Higiene.

Tais conhecimentos não possuem apenas uma natureza especulativa, mas estão voltados também para a intervenção no seio da vida do indivíduo e da sociedade, seja essa uma "therapeutica moral" de tipo médico ou uma "direção espiritual" de tipo religioso, ou ético. Desse modo, configura-se com clareza cada vez maior a função e a utilidade específica do estudo dos problemas da subjetividade, no âmbito da sociedade e da cultura brasileira da época. Em 
particular, no contexto do processo de organização do País como Estado moderno, os conhecimentos psicologicos colocam-se entre os recursos técnicos-práticos necessários para garantir o controle da vida social e a formação dos indivíduos enquanto cidadãos.

Outro fato muito significativo a ser destacado no âmbito da cultura carioca do século XIX, é o comparecer da matéria "Psychologia" como parte específica do programa do curso filosófico do Colégio D. Pedro II, a partir de 1850, sinal este da relevância reconhecida a essa área de estudo e do esboçar-se de uma identidade peculiar dela entre as outras disciplinas de matriz filosofica.

Em suma, observa-se que a cidade do Rio, na época considerada, representa um terreno fecundo para o processo de consolidação da Psicologia brasileira, cujos efeitos serão manifestos no fim do século XIX e principalmente no século XX.

Tabela 1: Programa de Curso e de Exames de Filosofia do Imperial Colégio D. Pedro II, para o $6^{2}$ ano de Filosofia, apresentado pelo Professor Joaquim Pinto Brasil, em 1850.

1. Objecto da Philosophia; e actualmente sua divisão.

2. Objecto da Psychologia; se he conveniente principiar por esta parte o estudo da Philosophia.

3. Se o Eu se distingue da alma; e como havemos de caracteriza-lo.

4. Enumeração e apreciação das propriedades essenciaes da alma e de suas faculdades.

5. Utilidade e importancia da Philosophia.

6. Relação de Philosophia com as outras Sciencias.

7-Se he ou não continua a actividade; e sendo, sua conciliação com a passividade.

8. Da unidade e simplicidade da alma.

9. Identidade pessoal.

10. Condições de identidade do Eu.

11. Idem.

12. Conciliação da variedade dos actos da alma com a identidade do Eu.

13. Noção, fé, relaçāo destes dous factos; juízo.

14. Em Ideologia qual das questōes se deve primeiro discutir, se a do estado presente das nossas idéias, se a da sua origem e formação. Estatística do pensamento. 


\section{Idem.}

16. Idéas inductivas a priori; caracter destas idéas.

17. Da indução a posteriori; e seu estado actual e primitivo.

18. Memoria em geral.

19. Idem.

20. Da sensibilidade, seu caracter, seu objecto em geral.

21. Comportamento da sensibilidade no prazer e na dor.

22. Exposição e apreciação dos phenomenos e movimentos analogos que tem lugar com a percepção do objecto tocante a sensibilidade.

23. Influencia da previdencia, memoria, e imaginação sobre a sensibilidade.

24. Idem.

25. Influencia do tempo sobre os phenomenos da força de sentir.

26. Da liberdade, se he verdadeiramente huma faculdade; seu objecto.

27. Gráos de manifestação da liberdade.

28. Idem.

29. Concurso da deliberação e determinaçāo para se constituir a liberdade.

30. Abusos do fatalismo.

31: Idem.

32. Demonstração da liberdade.

33. Influência recíproca das faculdades da alma.

34. Idem.

35. Da união da alma com o corpo.

36. Idem.

37. Apreciação das opiniōes acerca do comercio entre a alma e o corpo.

38. Idem.

39. Da associação das idéas.

40. Conciliação da presciência divina com a liberdade do homem.

(Programmas de Exames e de Curso do Imperial Collegio de Pedro II. Rio de Janeiro: Typ. Imperial, 1850, p. 30-31) 
Tabela 2: Programa de Exames de Filosofía do Imperial Colégio Dom Pedro II elaborado em 1851 pelo Professor Frel Jose de Santa Maria Amaral.

1. Objecto da Philosophia, e sua divisão.

2. Precedência das questões pychologicas.

3. Natureza dos phenomenos de que ellas dependem.

4. Meio pelo qual nos podemos assegurar delles.

5. Ordens em que devem ser distribuidos.

6. Da passividade e actividade do principio cogitante.

7. Das tres faculdades primordiaes.

8. Da concomitancia dos seus actos.

9. De sua mutua influencia.

10. Do eu, sua unidade e identidade.

11. Das differentes operaçōes do entendimento.

12. Da percepçāo, consciencia e razāo.

13. Da evidência e do juízo.

14. Da intuição e reflexão.

15. Da attenção e comparaçāo.

16. Da abstração e da generalização.

17. Da indução e analogia.

18. Da dedução e natureza do raciocínio.

19. Da memoria, reminiscência e imaginação.

20. Da faculdade de compor e associar idéias.

21. Da natureza das paixōes e sua origem.

22. Como se compōe com as lembranças, previsões e imaginaçōes.

23. Como vigorão e se desvanecem as paixōes.

24. Da sensibilidade physica e moral.

25. Dos instinctos de curiosidade, sociabilidade e compaixâo.

26. Do appetite sensitivo e racional.

27. Das affeicçōes interessantes e generosas.

28. Dos prazeres que devem formar a felicidade humana.

29. Da actividade espontanea e voluntária.

30. Dos factos constitutivos da vontade humana.

31. Da liberdade, coacção e indifferença.

32. Da liberdade vista pela consciência. 
33. Da liberdade deduzida dos factos da natureza moral.

34. Da liberdade demonstrada indirectamente.

35. Como os motivos influem na vontade.

36. Se 0 acto livre pode ser previsto.

37. Distincção da alma e do corpo.

38. Hypothese da assistencia.

39. Hypothese da harmonia prestabelecida.

40. Hypothese do influxo physico.

(Propramma para Exames, Imperial Collegio Pedro II, 1851, p. 31).

Tabela 3: Programa da "Psychologia" do Imperial Colégio Dom Pedro II, proposto em 1870 pelo Professor Frel Saturnino de Santa Clara Antunes de Abreu.

1. Objecto, utilidade e divisão da Phisolophia, sua utilidade e relação com as mais sciencias.

2. Das faculdades da alma: sensibilidade, entendimento, vontade.

3. Da sensibilidade: seus caracteres; sensaçōes, sentimentos, paixōes.

4. De nossas idéas em geral; suas diversas especies.

5. Da percepçāo exterior, da attenção e comparaçāo.

6. Da abstração, formação de ideas geraes.

7. Da memoria, associação das idéas, imaginação.

8. Do juízo e do raciocinio.

9. Dos signaes e em particular dos vocabulos, sua relação com o pensamento.

10. Da actividade espontanea e reflexa, descrição dos actos da vontade.

(Plano e Programa de Ensino no Imperial Collegio de Pedro II, 1870, p. 51) 


\section{Referencias Bibliograficas}

ALBERS, J.F.H. Dous meios mecanicos proprios a moderar os accessos da epilepsia ou cural-os, Annaes Brasilienses de Medicina, Rio de Janeiro: Typografia Imparcial, 1853, 2:192. Traduçăo de revista estrangeira.

AMARAL, M.J. Tratado Elementar de Matéria Médica, segundo a Doutrina de Cullen. Rio de Janeiro: Typografia Imperial Plancher, 1872 , tomos 1 e 2, $1{ }^{1}$ ediçáo.

BARBE, P.E. Cours Elémentaire de Philosophie a Pusage des etablissement d'education. Paris: Lecoffre, 1852, tomos 1 e 2, 2' ediçâo.

BARBIER, J.B.G. Algumas palavras sobre o homem moral. Annaes Brasilienses de Medicina. Rio de Janeiro: Typografia Imparcial, 1853, 9, 211-218. Tradução de revista estrangeira.

BONTEMPO, J.M. Compêndio de Matéria Médica. Rio de Janeiro: Regia Officina Typografica, 1814, $1^{1}$ ediçáo.

BONTEMPO, J.M. Compêndios de Medicina Prática feitos por ordem de Sua Alteza Real. Río de Janeiro: Regia Officina Typografica, 1815, $1^{1}$ edição.

BONTEMPO, J.M. Trabalhos médicos offerecidos à Majestade D. Pedro II. Rio de Janeiro: Typografia Nacional, 1825, a , 1' ediçăo.

BONTEMPO, J.M. Planos da Academia Médica- Cirurgica. Rio de Janeiro: Regia Officina Typografica, 1825, $\underline{b}, 1^{1}$ ediçăo.

CHARMA, A. Questões de Philosophia conteudas no Programa adotado para o Exame de Bacharelado em Letras da Universidade de Paris. Pernambuco; Guimarảes e Oliveira, 1860. Tradução em língua portuguesa de A. Herculano de Souza Bandeira.

COSTA, A.R. Curso Elementar de Philosophia, redigido segundo o Programa oficial para o ensino nos Lyceus do Reino. Porto: Teixeira, 1866, 2 volumes, 1 ' ediçấo.

DAMIROM Ph. Cours de Philosophie (Premiére Partie: Psychologie), 2 tomos, Paris, Hachette, 1837.

DEVAY, F. Estudos sobre alguns signaes precursores ou prodromos das moléstias graves do cérebro, consideradas de baixo da relação clínica, physiologica e medico legal. Annaes Brasilienses de Medicina. Rio de Janeiro: Typografia Imparcial, 1851, 6, (1), 186-192. Tradução de revista estrangeira.

DIRECTOR DA INSTRUCÇĀO DE $1^{\circ}$ E $2^{\circ}$ GRAU DO MUNICÍPIO DA CORTE. Plano e Programas de Ensino e de Exames do Imperial Collegio

Paidéia, FFCLRP - USP, Rib. Preto, 4, Fev/Jul, 1993. 
de Pedro II. Rio de Janeiro: Typografia Nacional, 1850; 1851; 1658; 1870; 1876; $1877 ; 1879 ; 1881 ; 1882$.

DORIA, E. Memória Histórica do Collegio Pedro II, 1837-1937. Rio de Janeiro: Ministério da Educação, 1937, 1 ' edição.

FERREIRA, S.P. Preleccōes Filosoficas. 1' edição: Rio de Janeiro: Régia Officina Typografica, 1815; $2^{2}$ edição, São Paulo: Editora Universidade de São Paulo-Grijalbo, 1970.

FERREIRA, S.P. Noçōes Elementares de Philosophia, Geral e Applicada às Sciencias Moraes e Políticas, Ontologia, Psychologia e Ideologia. Paris, Bailliére, 1839.

GAUME, Pe J. Manual dos Confessores. 2a edição. Trad. port., Porto, Casa de Cruz Coutinho, 1862, p. 349.

GAUTHEY, D.F.F. De l'Education ou Principes de Pédagogie Chrétienne. Paris: Mayrueis, 1854, Tomos 1 e 2, 1 'ediçăo.

GENOVESI, A. Instituiçōes de Metaphisica. $3^{3}$ edição port., Lisboa, Typografia Augusto, 1835, 416p.

HOMEM, S.T. Do Sistema penitenciário nos Estados Unidos. Minerva Brasiliense. Rio de Janeiro: Cabral, 1844, 1(5), 131-132.

LA COUR, J.P. Ensaio sobre a Therapeutica Moral. Tese de Doutorado, Faculdade de Medicina. Rio de Janeiro: Laemmert, 1863.

LAPA, R.R. Augmento das alienaçōes mentaes em França. Arquivo Médico Brasileiro. Rio de Janeiro: Typografia do Arquivo Médico Brasileiro, 1846, 47, tomo III, $1,24$.

LINGUORI, A.M. Oeuvres Complètes. Paris: Desbarres, 1842.

MACHADO, R. Da Noção da Norma, Medicina Social e constituição da Psiquiatria no Brasil. Rio de Janeiro: Graal, 1978 (Série Saber e Sociedade, n.3), 1'edição.

MAGALHÃES, J.D.G. Factos do Espírito Humano. Rio de Janeiro: Garnier, $1865,2^{\mathfrak{a}}$ edição.

MAGAlHÃES, J.D.G. A Alma e o Cérebro. Estudos de Psychologia e Physiologia. Rio de Janeiro: Garnier, 1876, 1' edição.

MIRVILLE, J.E. Pneumatologia. Das Esprits. Paris: Vrayet de Surcy, 1854, tomo $1,3^{\circ}$ edição.

MORAES, A.J.M. Physiologia Pathologica da Loucura. Guanabara. Rio de Janeiro, Impressora da Casa Imperial, 1854, tomo III, pp. 47-50; 85-96; 109-115; 126-129; 172-177; 202-206. 
MORAES, A.J.M. Medicina das Paixōes (Das Paixōes como causas de Moléstias). Medico do Povo na Terra de Santa Cruz. Rio de Janeiro: Typ. Brasileira, 1864, 1(5), 1-2.

MORAES, A.J.M. Physiologia das Paixōes e Affeicōes. 2" edição, Rio de Janeiro, Fauchor e Dupont, 1869, 56p.

PELLISSIER, M. Précis d'un Cours Complet de Philosophie Elémentaire. Paris:

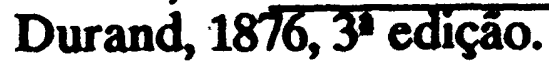

Plano e Regulamento dos Estudos para a Congregação de São Bento de Portugal. Lisboa, Regia Officina Typográfica, 1789.

REGO, J.P. Da hypocondria na primeira infância. Annaes Brasilienses de Medicina. Rio de Janeiro: Typ. Paula Brito, 1851, б(1), 2-10.

RIBEIRO, S.N. Concurso à Cadeira de Philosophia. Minerva Brasiliense. Rio de Janeiro: Cabral, 1844, 2(18), 547-550 (a).

RIBEIRO, S.N. Concurso a Cadeira de Philosophia. Minerva Brasiliense. Rio de Janeiro: Cabral, 1844, 2(20), 609-614 (b).

RIBEIRO, S.N. Concurso à Cadeira de Philosophia. Minerva Brasiliense. Rio de Janeiro: Cabral, 1844, 2(21), 642-648 (c).

RODRIGUES, J.J. Estatística da loucura, em Inglaterra. Arquivo Médico Brasileiro. Rio de Janeiro: Typ. Arquivo Médico Brasileiro, 1845, tomo II, p. 118.

ROSMINI, A.S. Nuovo Saggio sull'Origine delle idee. Milano: Pogliani, 1836, 3 volumes.

SANSEVERINI, C. Elementos Philosophiae Christianae cum Antigua et Nova Comparatae. Napoli: Manfredi, 1862, 3 volumes, $1^{1}$ edição.

SANTA GELTRUDES, Frei P.; QUEIROZ, J.; PEREIRA, J.J.; COUTO, A.M. Theses Philosophicas sobre a Psychologia do Homem, as quaes se propoem defender em público no Imperial Seminário de Sāo Joaquim. Rio de Janeiro: 'Typ. da Astrea, 1830, $1^{\circ}$ edição.

SCAVINI, P. Theologia Moralis Universa ad Mentem S. Alphonsi M. de Liguori. Paris: 1850, 4 volumes, 1 ediçáo.

SIMONI, L.V. Trabalhos da Sociedade da Academia Nacional de Medicina. Rio de Janeiro: Typografia Imperial, 1831.

SCARES, S.F. Preleccooes de Moral, particular e páblica ou Pensamentos Philosophicos sobre o christianismo, moral e política. Rio de Janeiro: Laemmert, 1863. 
SOUZA, J.S. Compêndio de Philosophia, ordenado segundo os Princípios e Methodo do Dr. Angelico S. Thomaz de Aquino. Recife: Typografia da Esperança, 1867, $1^{1}$ ediçảo.

SOUZA, J.S. Licões de Philosophia Elementar Racional e Moral. Recife, Liv. Academica, 1871, 1 edição.

SULPIZI, P. Compendium Philosophiae ad usum Seminariorum. Paris: Lecoffre, 1864, 3 volumes, 7 ediçăo.

TONGIORGI, S. Institutiones Philosophicae. Roma: Morini, 1862.

\section{SUMMARY}

The object of the article is the psychological knowledge produced and transmitted in the Institutions od Higher Education and Secondary Schools in the city of Rio de Janeiro during 19th (until 1870), loking at heir conceptual signification and social function in the ambit of Brazilian spciety of that time, as a critical analysis.

A survey using sources about some of the most important Education Institutions of Rio de Janeiro in the 19th century was made, allowing a reconstruction of the psychological contents and practices of these Institutions. A coexistence of different proposals for doctrinal apnroaches, methodological focuses and aimed objects were presented.

Palavras-chaves: História da Psicologia no Brasil

Ensino da Psicologia no Brasil, Psicologia no Rio de Janeiro no século XIX. 